\title{
Allochthonous brown algae are the primary food source for consumers in a temperate, coastal environment
}

\author{
Karen R. Crawley ${ }^{1,4, *}$, Glenn A. Hyndes ${ }^{1}$, Mathew A. Vanderklift ${ }^{1,2}$, \\ Andrew T. Revill ${ }^{3}$, Peter D. Nichols ${ }^{3}$ \\ ${ }^{1}$ Centre for Marine Ecosystems Research, School of Natural Sciences, Edith Cowan University, Joondalup, \\ Western Australia 6027, Australia \\ ${ }^{2}$ CSIRO Marine and Atmospheric Research, Floreat, Western Australia 6014, Australia \\ ${ }^{3}$ CSIRO Marine and Atmospheric Research, Hobart, Tasmania 7001, Australia \\ ${ }^{4}$ Present address: Oceanica, PO Box 3172, Broadway, Nedlands, Western Australia 6009, Australia
}

\begin{abstract}
In several parts of the world, detached seagrass and macroalgae accumulate in the surf zone where in situ primary production can be low. This allochthonous resource is therefore likely to be important to consumers, but the various components of the resource likely play different roles in the food webs. We traced sources of production for the abundant amphipod Allorchestes compressa and 2 key predatory fishes in the surf zone of southwestern Australia using multiple stable isotopes $\left(\delta^{13} \mathrm{C}, \delta^{15} \mathrm{~N}\right.$ and $\left.\delta^{34} \mathrm{~S}\right)$ and fatty acids. Seagrasses had higher $\delta^{13} \mathrm{C}$ than macroalgae, while $\delta^{13} \mathrm{C}$ of red and brown macroalgae were similar. Mixing models based on $\delta^{13} \mathrm{C}$ were ambiguous and indicated that brown algae and seagrasses were both feasible carbon sources for A. compressa. $\delta^{15} \mathrm{~N}$ varied little between seagrasses and macroalgae, while $\delta^{15} \mathrm{~N}$ of amphipods was higher and $\delta^{15} \mathrm{~N}$ of fish higher again. $\delta^{34} \mathrm{~S}$ was not useful in distinguishing between macrophytes or trophic levels. The fatty acid composition of brown and red algae and seagrasses were distinct. The composition of essential fatty acids (i.e. fatty acids that the consumer must obtain through its diet) of $A$. compressa was most similar to that of brown algae. The combination of stable isotope and fatty acid analyses indicates that, although brown algae comprises a lower proportion of wrack biomass than seagrass (17 to $28 \%$ vs. 52 to $58 \%$ ), brown algae, particularly the kelp Ecklonia radiata, contributes disproportionately to the surf-zone food web in southwestern Australia.
\end{abstract}

KEY WORDS: Wrack $\cdot$ Stable isotopes $\cdot$ Fatty acids $\cdot$ Spatial subsidy $\cdot$ Surf zone Resale or republication not permitted without written consent of the publisher

\section{INTRODUCTION}

The movement of nutrients and detritus across habitat boundaries allows consumers to achieve greater abundances than when supported by in situ production alone, sometimes to the extent that they profoundly alter food web structure and community dynamics (Polis \& Hurd 1996, Polis et al. 1997). Such connectivity can occur through a number of pathways. For example, terrestrial ecosystems can receive inputs of guano from seabirds (Polis \& Hurd 1996) or marine macrophytes through water movement (Ince et al. 2007). Considerable effort has gone into understanding the ecological influence of the transfer of nutrients and detritus from marine to terrestrial ecosystems, but less is known about the effects of transfers across marine boundaries (Colombini \& Chelazzi 2003).

In many coastal regions, the production of marine macroalgae and seagrasses in subtidal habitats is extremely high. During storms and high swells, macrophytes are detached and transported to distant areas, often crossing habitat boundaries (Kirkman \& 
Kendrick 1997, Colombini \& Chelazzi 2003). Detached macrophytes, known as wrack, often accumulate along shorelines (Pennings et al. 2000, Ince et al. 2007). Since sandy shorelines often have very little in situ primary production (Brown \& McLachlan 1990), accumulations of wrack provide a significant additional potential food source for consumers.

Our ability to separate the importance of allochthonous and autochthonous sources of production relies on reliable discrimination between multiple food sources. Stable isotopes (e.g. of carbon, nitrogen and sulfur) are frequently used to identify sources of production, and to delineate trophic pathways (e.g. Peterson \& Howarth 1987, Moncreiff \& Sullivan 2001). However, when the stable isotope ratios of potential food sources do not differ greatly, results are typically ambiguous, making it difficult to provide clear conclusions (e.g. Lepoint et al. 2000, Hyndes \& Lavery 2005). To help resolve uncertainty in these situations, lipid biomarkers such as fatty acids can be used (Phleger et al. 1998, Wilson et al. 2001). The combined use of stable isotopes and fatty acids can therefore be useful to establish sources of production.

Like many other parts of the world (Colombini \& Chelazzi 2003), allochthonous wrack accumulates in large quantities in the surf zones along the shores of southwestern Australia, where it is an important food source for abundant grazers, particularly amphipods and isopods. The amphipod Allorchestes compressa is the dominant mesograzer in detached macrophyte accumulations in southwestern Australia, although its abundance varies greatly across space and time (Robertson \& Lucas 1983, Crawley \& Hyndes 2007). This amphipod utilises wrack for food and habitat and in turn provides food for several species of fishes, particularly juvenile Cnidoglanis macrocephalus (Plotosidae) and Pelsartia humeralis (Teraponidae), which are enhanced in abundance with increases in the amount of wrack in surf zones (Crawley et al. 2006). Since amphipods can have distinct dietary preferences (Pennings et al. 2000, Crawley \& Hyndes 2007), different wrack components may play substantially different roles in the surf-zone environment. The aim of the present study was to use multiple stable isotopes $\left(\delta^{13} \mathrm{C}\right.$, $\delta^{15} \mathrm{~N}$ and $\delta^{34} \mathrm{~S}$ ) together with fatty acid profiles to establish which type(s) of allochthonous material (brown algae, red algae or seagrass) provide the major source(s) of energy and nutrition for this food chain.

\section{MATERIALS AND METHODS}

Study area and sample collection. The study region was located on the lower west coast of Australia (Fig. 1), where most of the coastline consists of open sandy beaches exposed to low to moderate energy waves. A more severe wave climate exists during the austral winter and spring, when south to southwesterly swells predominate (Lemm et al. 1999). Large wrack accumulations are a prominent feature on many sandy beaches in the region, particularly during late autumn to early spring (Kirkman \& Kendrick 1997). Detached macrophytes, amphipods (Allorchestes compressa) and fish (Cnidoglanis macrocephalus and Pelsartia humeralis) were collected at 3 locations in the study region (Two Rocks, Hillarys and Shoalwater Bay) in winter 2004. Detached macrophytes included the macroalgae Ecklonia radiata and Sargassum sp. (Phaeophyta), Hypnea ramentacea and Laurencia filiformis (Rhodophyta) and the seagrasses Posidonia sinuosa and Amphibolis griffithii (Magnoliophyta). Samples were collected from fresh accumulations of detached macrophytes at each location, except at Two Rocks, where senesced, but not fresh, $P$. sinuosa was present. Where possible, 5 individual leaves or thalli of each macrophyte species were collected. Since speci-

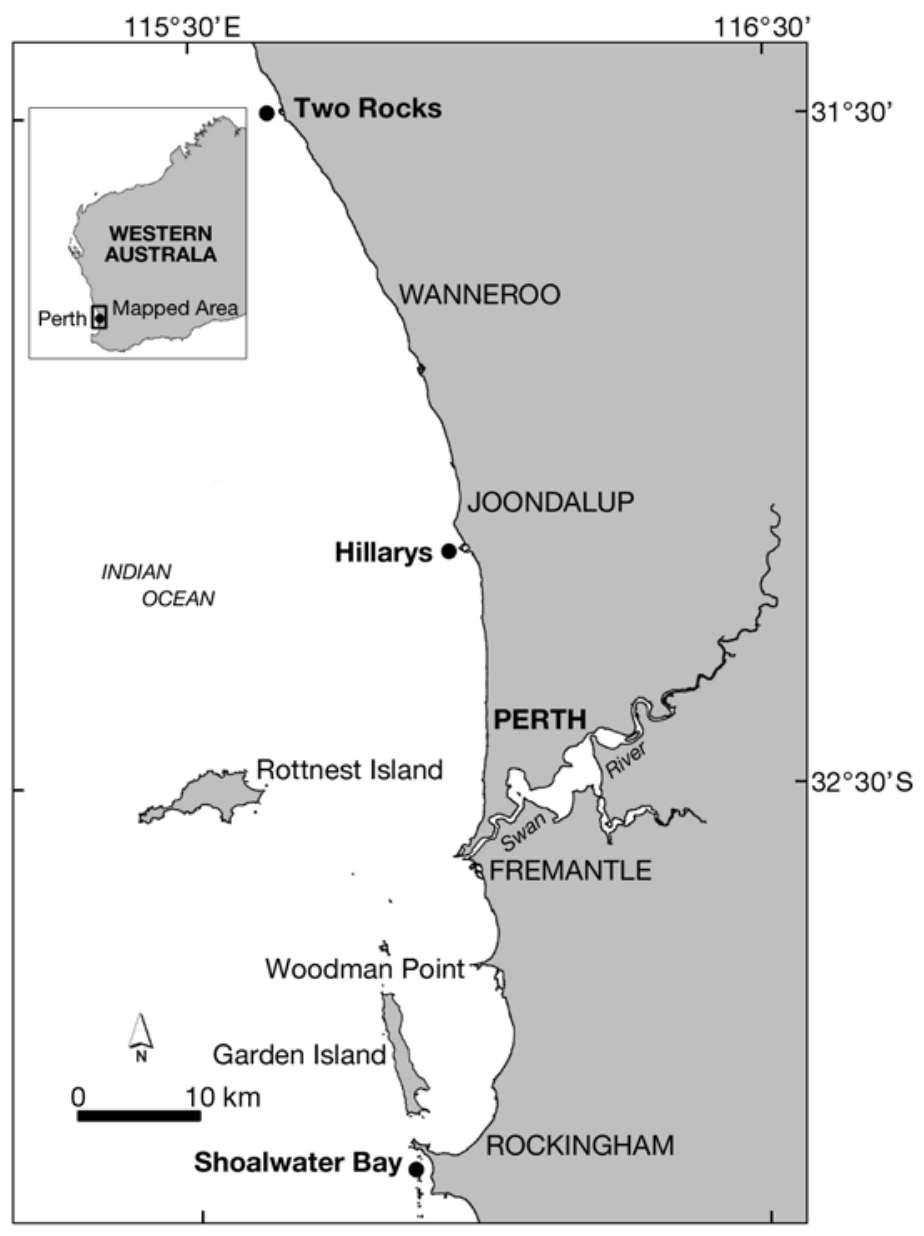

Fig. 1. Study area: Two Rocks, Hillarys and Shoalwater Bay in southwestern Australia 
mens of the genus Sargassum could not be identified to species level due to the lack of reproductive structures, they are referred to by their genus name.

Amphipods were collected at each site from within surf-zone wrack using a plankton net (153 $\mu \mathrm{m}$ mesh size) scooped through the wrack on 3 different occasions, approximately 2 wk apart, during winter 2004. Amphipods identified as Allorchestes compressa were later removed from wrack in the laboratory using a light microscope. Due to the small size of the amphipods, approximately 150 to 200 amphipods from each sampling occasion were pooled into a single sample to provide sufficient material for analyses. Pooled amphipods from each occasion were considered replicates.

Fish were collected from within surf-zone wrack accumulations at each site using a $21.5 \mathrm{~m}$ seine net (9 $\mathrm{mm}$ wing mesh and $6 \mathrm{~mm}$ bunt mesh), at the same time as the macrophytes. Where possible, 5 individuals of juvenile Cnidoglanis macrocephalus and Pelsartia humeralis were collected at each site, since fish assemblages in surf-zone wrack in this region primarily comprise juveniles of these 2 species (Crawley et al. 2006).

To examine the relative proportions of seagrass and brown, red and green algae at each site, wrack was surveyed using a phytoplankton net (153 $\mu \mathrm{m}$ mesh size, $30 \mathrm{~cm}$ diameter, $1 \mathrm{~m}$ length) during winter 2004. The net was scooped through the water 3 times for each replicate, with 3 random replicates taken from each site. Macrophyte material from each replicate was identified as seagrass or brown, red or green algae and dried at $60^{\circ} \mathrm{C}$ for $48 \mathrm{~h}$. Dry weights of each broad taxonomic group were recorded.

Stable isotope and fatty acid analyses. Macrophyte samples were scraped using a razor blade to remove epiphytes when necessary and stored frozen at $-20^{\circ} \mathrm{C}$. Amphipods were kept in filtered seawater overnight to clear their gut contents before being frozen. Dorsal muscle tissue was dissected from the side of each fish which had been frozen after capture. All samples were rinsed in deionised water, dried at $60^{\circ} \mathrm{C}$ for $48 \mathrm{~h}$, homogenised in a ball-mill for 2 to 3 min until ground to a fine powder and weighed in tin capsules (Elemental Microanalysis).

$\delta^{13} \mathrm{C}$ and $\delta^{15} \mathrm{~N}$ values of macrophytes, amphipods and fish were determined using a Europa Scientific ANCA-NT 20-20 isotope ratio mass spectrometer. $\delta^{13} \mathrm{C}$ and $\delta^{15} \mathrm{~N}$ of the plant and animal samples were determined by comparison with plant and fish laboratory standards, respectively, which had been previously calibrated against standard International Atomic Energy Agency (IAEA) or National Institute of Standards and Technology (NIST) reference materials with a precision of $<0.1 \%$. All $\delta^{13} \mathrm{C}$ and $\delta^{15} \mathrm{~N}$ results, expressed in \%, are traceable to the internationally accepted Vienna PeeDee Belemnite (VPDB) or atmospheric $\mathrm{N}_{2}$ scales. Prior to analysis, subsamples of amphipods were acid-treated using $1 \mathrm{~N} \mathrm{HCl}$ until effervescence ceased, indicating that carbonate had been removed (Boutton 1991). Acidified amphipod subsamples were analysed for $\delta^{13} \mathrm{C}$ and the untreated portion analysed separately for $\delta^{15} \mathrm{~N}$. $\delta^{34} \mathrm{~S}$ was determined by Iso-Analytical (UK) using elemental analysis coupled with isotope ratio mass spectrometry (EA-IRMS). The samples were weighed in tin capsules and vanadium pentoxide was added as a catalyst before sealing. $\delta^{34} \mathrm{~S}$ was determined by monitoring the specific mass to charge ratio, $\mathrm{m} / \mathrm{z} 48,49$ and 50 , of $\mathrm{SO}^{+}$ produced from $\mathrm{SO}_{2}$ in the ion source and comparing it to NBS-127 (barium sulfate, Vienna Canyon Diablo Troilite) reference material distributed by the IAEA. Three of the 5 replicate samples for each species were randomly selected for sulfur isotope analysis.

For lipid analyses, 3 replicate samples for each macrophyte and animal species from each site were pooled to give a single sample of approximately $25 \mathrm{mg}$ total dry weight. Samples were extracted quantitatively overnight by a single-phase chloroform/ methanol/water method (Bligh \& Dyer 1959) modified by substituting dichloromethane for chloroform, with 5,(H)-cholan-24-ol (Chiron AS) added as an internal standard. After phase separation, lipids were recovered in the lower dichloromethane layer and concentrated by rotary evaporation to provide the total extract (TE). The TE was evaporated under a stream of nitrogen and the total non-saponifiable neutral lipid and fatty acid fractions were obtained by treatment with $3 \mathrm{ml} 5 \%$ potassium hydroxide (BDH Laboratory Supplies; AnalaR) in 80:20 methanol/water (Mansour et al. 2005). Non-saponifiable lipids were converted to their corresponding O-trimethylsilyl (O-TMS) ethers by treatment with bis(trimethylsilyl)trifluoroacetamide (BSTFA, $100 \mu \mathrm{l}, 60^{\circ} \mathrm{C}, 60 \mathrm{~min}$ ) (Alltech Associates; $99+$ $1 \%$ trimethylchlorosaline [TMCS]). FA and bile acids were converted to their corresponding methyl esters by treatment with a methanol-hydrochloric acid-chloroform (10:1:1 v/v/v) solution (Mansour et al. 2005).

Gas chromatography (GC) was performed using a Varian 3800 chromatograph equipped with a flame ionization detector (FID) and septum-equipped programmable injector (SPI). The chromatograph was equipped with a $50 \mathrm{~m} \times 0.32 \mathrm{~mm}$ (inner diameter) cross-linked $5 \%$ phenyl-methyl silicone (HP5 ultra 2) fused-silica capillary column, with helium as carrier gas. Operating conditions are described in Mansour et al. (2005). C23:0 tricosanoic fatty acid methyl ester (FAME) was added as an internal injection standard. Peak identifications were based on comparison of retention times with authentic and laboratory standards and GC-mass spectrometric (GC-MS) analy- 
sis. Data were acquired and peak areas quantified using Varian Galaxie chromatography software. Verification of the identity of individual components was performed on a Thermoquest/Finnigan GCQ-Plus benchtop mass spectrometer fitted with a direct capillary inlet and an on-column injector (Mansour et al. 2005). The detection limit was $\approx 10 \mathrm{ng}$.

To determine whether oven drying affected the fatty acid composition of different taxa, 3 replicate samples of the algae Ecklonia radiata and Laurencia sp., the seagrass Posidonia sinuosa and the amphipod Allorchestes compressa were collected from wrack at Shoalwater Bay. Sample processing was identical to that described above, except each replicate sample was divided in half, with one half oven-dried at $60^{\circ} \mathrm{C}$ and the other half freeze-dried. Samples for both drying treatments and each taxon were then analysed for fatty acid profiles using the methods described above.

Statistical analyses. Green algae constituted an exceptionally minor portion of the wrack (see 'Results'), so were not included in subsequent analyses. To test whether variation in $\delta^{13} \mathrm{C}, \delta^{15} \mathrm{~N}$, and $\delta^{34} \mathrm{~S}$ was greatest for differences among divisions of macrophytes (i.e. brown algae, red algae and seagrass hereafter referred to simply as 'divisions'), rather than for differences among species, we used nested ANOVA to test for differences between levels of the 2 possible sources of variation: division (fixed effect, 3 levels) and species (nested in division, 2 levels). We conducted separate analyses for each site and element and we kept $\mathrm{n}=3$ for each analysis to maintain a balanced design. We were most interested in determining which source was associated with the greatest amount of variability, and focussed on magnitudes of effects $\left(\omega^{2}\right)$ because, unlike p-values, this does not depend directly on the degrees of freedom (Graham \& Edwards 2001).

Stable isotope values were used to calculate mixing models, using the software IsoSource (Phillips \& Gregg 2003). Since the inclusion of $\delta^{15} \mathrm{~N}$ and $\delta^{34} \mathrm{~S}$ in the calculations did not generate feasible outcomes at any of the sites, only $\delta^{13} \mathrm{C}$ was used. Calculations based on $\delta^{13} \mathrm{C}$ alone did not yield feasible outcomes for Shoalwater Bay. As a result, mixing model analyses were restricted to $\delta^{13} \mathrm{C}$ values for Two Rocks and Hillarys. These models estimated the potential contribution of the 3 potential food sources within the wrack (brown algae, red algae and seagrass) to the first order consumer Allorchestes compressa. The frequency and range of the possible contributions (0 to $100 \%$ ) of different types of macrophytes at increments of $1 \%$ were determined. The $\delta^{13} \mathrm{C}$ values of each of the 3 potential sources were adjusted based on the expected discrimination $(-10,-3.5$ and $-3 \%$ for seagrass, red algae and brown algae, respectively), using data for A. compressa fed controlled diets of each food type in the laboratory (Crawley et al. 2007).

The fatty acids present in each species of macrophyte and consumer were expressed as relative abundance of the total fatty acids (percentage of the total area of fatty acids). We used permutational MANOVA (PERMANOVA; Anderson 2001) to test whether variation in the composition of fatty acids was predominantly due to differences among divisions or species. The analysis used Bray-Curtis dissimilarities calculated from untransformed data. As with univariate analyses, we were most interested in the amount of variation attributable to the different sources, and focussed on estimates of the pseudo-variance components, calculated as for the univariate case from the means squares yielded by PERMANOVA (Anderson \& Millar 2004). To visualise multivariate patterns we generated a generalised discriminant analysis using Canonical Analysis of Principal Coordinates (CAP) (Anderson \& Willis 2003). To explore which fatty acids contributed most to differences among divisions, we correlated the fatty acid data with the canonical axes.

Essential fatty acid ( $\omega 3$ and $\omega 6$ polyunsaturated fatty acids [PUFA]) data were ordinated using nMDS to examine patterns of similarity in essential fatty acid (EFA) composition among different macrophyte taxa and consumers. The ordination was performed using Primer 5 (Clarke \& Gorley 2001) based on Bray-Curtis similarities calculated from untransformed data. One Hypnea ramentacea sample from Shoalwater Bay was excluded from the analysis as it did not contain any EFA, as well as one Posidonia sinuosa sample from Two Rocks, which was more decomposed than those at the other sites. Similarity of percentages (SIMPER) was used to determine the degree of dissimilarity between macrophyte taxa and the first order consumer Allorchestes compressa.

A non-metric multi-dimensional scaling (nMDS) ordination plot (constructed using PRIMER v.5, based on a Bray-Curtis similarity matrix derived from squareroot transformed data (Clarke \& Gorley 2001) reflected the tight clumping of samples for each taxon on the nMDS plot regardless of drying treatment, indicating that oven drying at $60^{\circ} \mathrm{C}$ does not affect the relative level of similarity among the taxa examined. A 2-way crossed ANOSIM (with 100 permutations) was used to test for differences among taxa and drying treatment to support the nMDS and showed that there was no effect of drying treatment $(R=0.139, p=0.96)$, but that fatty acid composition still differed among taxa $(\mathrm{R}=$ $0.997, \mathrm{p}=0.001$ ). These results show that oven drying does not affect the conclusions of this study, and add further evidence to the robustness of fatty acid composition despite the treatment of samples (Phleger et al. 2007). 


\section{RESULTS}

\section{Wrack biomass}

Average \pm SE wrack biomass ranged between $140.4 \pm 19.7 \mathrm{~g}$ dry weight (DW) $\mathrm{m}^{-2}$ at Hillarys, $159.8 \pm$ $29.6 \mathrm{~g} \mathrm{DW} \mathrm{m}^{-2}$ at Shoalwater Bay and $189.4 \pm 31.4 \mathrm{~g}$ DW $\mathrm{m}^{-2}$ at Two Rocks. Seagrass contributed most to the biomass at each site, ranging between 52 and $58 \%$, while brown and red algae contributed 17 to $28 \%$ and 16 to $26 \%$, respectively. In comparison, green algae contributed only 0.3 to $0.6 \%$ to the total biomass.

\section{Stable isotopes}

Differences among divisions of macrophytes were the greatest source of variation in $\delta^{13} \mathrm{C}$ at all sites, accounting for $>67 \%$ of variation in each case (Table 1). In contrast, differences between species within each division accounted for a much lower proportion of variance $(\leq 15 \%)$. These patterns were less pronounced for $\delta^{15} \mathrm{~N}$ and $\delta^{34} \mathrm{~S}$. Differences in $\delta^{15} \mathrm{~N}$ among divisions accounted for more variation than differences among species at Two Rocks and Hillarys (where among-individual variation was greatest), but not at Shoalwater Bay. Differences in $\delta^{34} \mathrm{~S}$ among divisions were the greatest source of variation at Hillarys and Shoalwater Bay, but not at Two Rocks. In general, the results indicate that differences among divisions were greatest, so pooling species prior to calculation of mixing models was justified.

Student-Newman-Keuls (SNK) tests revealed that $\delta^{13} \mathrm{C}$ values of seagrasses were significantly higher than those of macroalgae at all locations (Fig. 2). $\delta^{13} \mathrm{C}$ values of brown algae were higher than those of red algae at Two Rocks, but differences between brown and red algae were not evident at the other 2 locations. $\delta^{13} \mathrm{C}$ of Allorchestes compressa was relatively consistent across locations, falling within the range encompassed by brown and red algae (range of location means $=-19.7$ to -21.6) (Fig. 2). $\delta^{13} \mathrm{C}$ values of the fishes Cnidoglanis macrocephalus (range $=-17.1$ to -19.8 ) and Pelsartia humeralis (range $=-17.8$ to -19.7 ) also fell within the range encompassed by brown and red algae (Fig. 2).

Differences in $\delta^{15} \mathrm{~N}$ values among divisions were not significant at any location (Table 1$). \delta^{15} \mathrm{~N}$ values of Allorchestes compressa were higher than all macrophytes (by at least 1\%), but lower than the 2 fish species (by approximately 6\%o) (Fig. 2). Similarly, $\delta^{34} \mathrm{~S}$ did not differ among divisions at all sites except Shoalwater Bay, where $\delta^{34} \mathrm{~S}$ of seagrass was significantly lower than brown and red algae. $\delta^{34} \mathrm{~S}$ values of $A$. compressa were within the range of most macrophytes at Hillarys and Shoalwater Bay, but not at Two Rocks (range $=16.0$ to 18.9 ) (Fig. 2). $\delta^{34} \mathrm{~S}$ values of Cnidoglanis macrocephalus (range $=12.7$ to 16.2 ) and Pelsartia humeralis (range $=16.2$ to 17.1 ) were typically most similar to $\delta^{34} \mathrm{~S}$ of seagrass (Fig. 2).

Mixing model results for all divisions at the 2 sites analysed spanned a wide range, encompassing zero in each case. At Two Rocks, brown algae and then seagrass ranked highly in terms of the contribution of $\delta^{13} \mathrm{C}$ to $\mathrm{Al}$ lorchestes compressa (Fig. 3). Both exhibited higher median potential contributions ( $>0.35$ ) and 99th percentiles $(>0.66)$ than red algae. In contrast, seagrass ranked highly at Hillarys (median value $=0.73$, 99th percentile $=$ 0.82 ), while brown algae ranked lower (median value $=$ 0.17, 99th percentile $=0.37$ ) (Fig. 3). At both sites, red algae provided a smaller potential contribution to A. Compressa (median values $<0.17$, 99th percentiles $<0.34$ ).

\section{Fatty acid composition}

A wide range of fatty acids was present in the macrophytes sampled (Table 2). Differences among divisions were the greatest source of variation in fatty

Table 1. Results of nested ANOVA testing for significance of variation among levels of 3 types of macrophytes (divisions) and between species within each division on $\delta^{13} \mathrm{C}, \delta^{15} \mathrm{~N}$ and $\delta^{34} \mathrm{~S}$. Bold: statistical significance at $\mathrm{p}<0.05 ; \omega^{2}$ : relative magnitude of effects

\begin{tabular}{|c|c|c|c|c|c|c|c|c|c|c|c|c|c|c|}
\hline \multirow[t]{2}{*}{ Site } & \multirow{2}{*}{$\begin{array}{l}\text { Source of } \\
\text { variation }\end{array}$} & \multirow[b]{2}{*}{$\mathrm{df}$} & \multicolumn{4}{|c|}{$-\delta^{13} \mathrm{C}$} & \multicolumn{4}{|c|}{$-\delta^{15} \mathrm{~N}$} & \multicolumn{4}{|c|}{$\delta^{34} \mathrm{~S}$} \\
\hline & & & MS & $F$ & $\mathrm{p}$ & $\omega^{2}$ & MS & $F$ & $\mathrm{p}$ & $\omega^{2}$ & MS & $F$ & $\mathrm{p}$ & $\omega^{2}$ \\
\hline \multirow[t]{3}{*}{ Two Rocks } & Division & 2 & 210.15 & 7.55 & 0.067 & 67.9 & 5.01 & 2.62 & 0.219 & 27.6 & 2.29 & 0.39 & 0.708 & 0 \\
\hline & Species & 3 & 27.83 & 3.63 & 0.045 & 15.0 & 1.91 & 1.78 & 0.205 & 14.9 & 5.88 & 4.53 & 0.024 & 44.7 \\
\hline & Residual & 12 & 7.67 & & & 17.1 & 1.07 & & & 57.5 & 1.30 & & & 55.3 \\
\hline \multirow[t]{3}{*}{ Hillarys } & Division & 2 & 170.79 & 14.79 & 0.028 & 79.6 & 4.60 & 3.34 & 0.172 & 33.1 & 31.43 & 3.83 & 0.149 & 43.0 \\
\hline & Species & 3 & 11.55 & 2.61 & 0.100 & 7.1 & 1.38 & 1.46 & 0.275 & 8.9 & 8.21 & 2.29 & 0.130 & 17.1 \\
\hline & Residual & 12 & 4.43 & & & 13.3 & 0.94 & & & 58.1 & 3.59 & & & 39.9 \\
\hline Shoalwater & Division & 2 & 113.65 & 13.70 & 0.031 & 80.7 & 6.54 & 1.50 & 0.353 & 15.0 & 12.40 & 14.24 & 0.029 & 78.6 \\
\hline \multirow[t]{2}{*}{ Bay } & Species & 3 & 8.30 & 3.86 & 0.038 & 9.4 & 4.36 & 4.70 & 0.022 & 46.9 & 0.87 & 2.51 & 0.109 & 7.1 \\
\hline & Residual & 12 & 2.15 & & & 9.9 & 0.93 & & & 38.1 & 0.35 & & & 14.2 \\
\hline
\end{tabular}



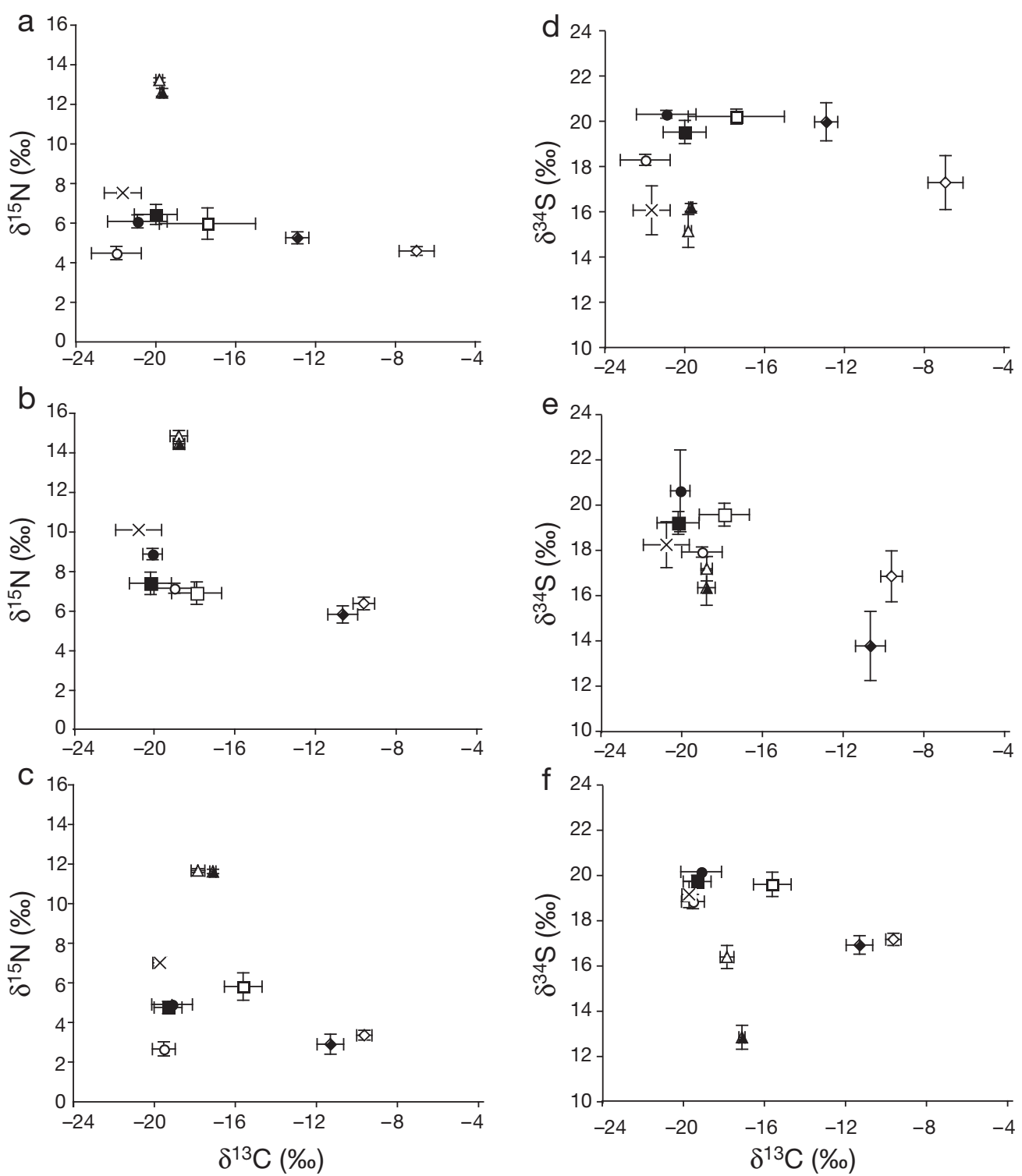

Fig. 2. Mean ( $\pm \mathrm{SE}, \mathrm{n}=4$ or 5) $(\mathrm{a}-\mathrm{C}) \delta^{15} \mathrm{~N}$ and $\delta^{13} \mathrm{C}$ and $(\mathrm{d}-\mathrm{f}) \delta^{34} \mathrm{~S}$ and $\delta^{13} \mathrm{C}$ of macrophytes (brown and red algae, and seagrasses), amphipods and fishes at (a,d) Two Rocks, (b,e) Hillarys and (c,f) Shoalwater Bay in southwestern Australia. Amphipod sample constitutes >1 amphipod. For full taxonomic names see 'Materials and methods - Study area and sample collection'

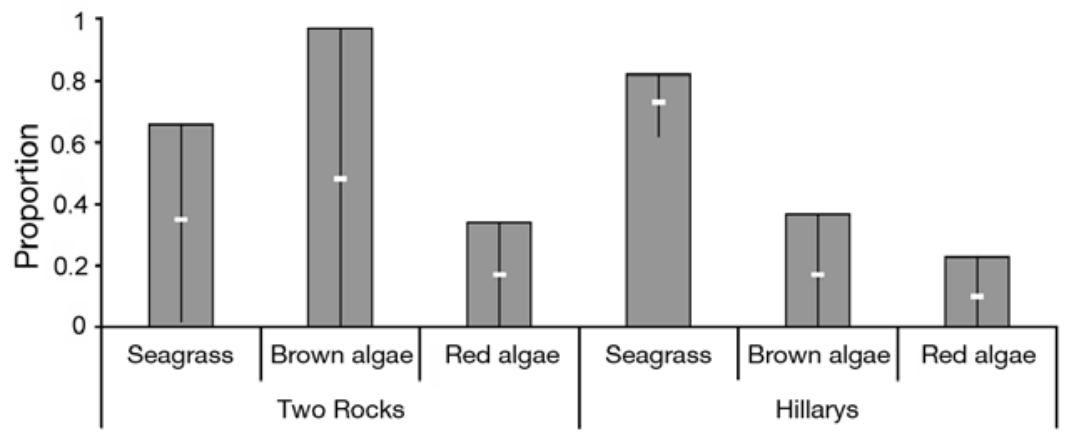

Fig. 3. Box-whisker plots representing the distribution of the feasible contributions of different macrophyte types to Allorchestes compressa at Two Rocks and Hillarys based on $\delta^{13} \mathrm{C}$ values (using $-10,-3.5$ and $-3 \%$ diet-consumer discrimination for seagrass, red algae and brown algae, respectively). Plots show 1st (bottom of whisker), 50th (white horizontal line) and 99th (top of whisker) percentiles and minimum and maximum values (grey box) of distributions 
acid composition, while differences among species within each division were minor (Table 3). The constrained ordination (CAP) showed clear separation of seagrass from brown and red algae along the first canonical axis and separation of brown algae and red algae along the second canonical axis (Fig. 4), reflecting the differences in fatty acid composition. Seagrasses (except for Posidonia sinuosa from Two Rocks, which was anomalous) were characterised by high levels of $17: 0$ (1.5 to $4.0 \%$ ), 18:0 (6.0 to $10.2 \%$ ) and $18: 2 \omega 6$ (18.4 to $32.1 \%$ ) relative to macroalgae (Table 2, Figs. 4 \& 5). Red algae were characterised by high levels of $16: 0$ (50.4 to $60.0 \%$ ) and $18: 1 \omega 7 \mathrm{C}$ (2.2 to $3.7 \%$ ). Brown algae were characterised by high levels of $20: 4 \omega 6$ (4.2 to $8.8 \%), 16: 1 \omega 7 \mathrm{C}$ ( 7.0 to $14.5 \%$ ) and $18: 4 \omega 3$ (0 to $3.2 \%$ ). Of the diagnostic fatty acids shown for macrophytes, all consumer species (amphipods and fish) contained particularly high levels of 16:0 (20.5 to $23 \%$ ), while fish contained moderate levels of 18:0 (9.3 to $12.3 \%$ ) (Fig. 5). Mode-

Table 2. Fatty acid composition (mean percent of total fatty acids \pm SE) for 6 species of detached macrophytes from 3 sites in southwestern Australia. PUFA: polyunsaturated fatty acids. For full taxonomic names see 'Materials and methods - Study area and sample collection'

\begin{tabular}{|c|c|c|c|c|c|c|}
\hline \multirow[t]{2}{*}{ Fatty acid } & \multicolumn{2}{|c|}{ - Phaeophyta -} & \multicolumn{2}{|c|}{ Rhodophyta } & \multicolumn{2}{|c|}{ Magnoliophyta } \\
\hline & $\begin{array}{l}\text { Laminariales } \\
\text { E. radiata }\end{array}$ & $\begin{array}{c}\text { Fucales } \\
\text { Sargassum sp. }\end{array}$ & $\begin{array}{l}\text { Gigartinales } \\
\text { H. ramentacea }\end{array}$ & $\begin{array}{l}\text { Ceramiales } \\
\text { L. filiformis }\end{array}$ & $\begin{array}{c}\text { Potamogetonales } \\
\text { P. sinuosa }\end{array}$ & A. griffithii \\
\hline \multicolumn{7}{|l|}{ Saturated } \\
\hline $14: 0$ & $6.6 \pm 1.4$ & $4.8 \pm 0.7$ & $7.3 \pm 2.6$ & $10.9 \pm 0.7$ & $1.0 \pm 0.6$ & $0.3 \pm 0.2$ \\
\hline $15: 0$ & $0.7 \pm 0.7$ & $0.9 \pm 0.1$ & $1.2 \pm 0.6$ & $0.9 \pm 0.2$ & $1.5 \pm 0.8$ & $0.2 \pm 0.2$ \\
\hline $16: 0$ & $37.6 \pm 2.7$ & $42.4 \pm 0.5$ & $52.6 \pm 1.9$ & $56.5 \pm 2.0$ & $36.8 \pm 7.2$ & $33.1 \pm 1.6$ \\
\hline $17: 0$ & $0.2 \pm 0.2$ & 0 & 0 & 0 & $1.1 \pm 0.6$ & $3.7 \pm 0.2$ \\
\hline $18: 0$ & $2.2 \pm 1.2$ & $1.6 \pm 0.2$ & $2.5 \pm 0.8$ & $1.6 \pm 0.8$ & $5.0 \pm 2.5$ & $8.1 \pm 1.2$ \\
\hline 19:0 & 0 & 0 & $3.6 \pm 3.6$ & 0 & $0.7 \pm 0.7$ & 0 \\
\hline $20: 0$ & $2.1 \pm 0.7$ & $0.4 \pm 0.1$ & 0 & 0 & $0.5 \pm 0.3$ & $0.3 \pm 0.2$ \\
\hline $22: 0$ & 0 & $0.8 \pm 0.4$ & 0 & 0 & $0.7 \pm 0.4$ & $0.4 \pm 0.3$ \\
\hline Total & $49.3 \pm 6.8$ & $50.8 \pm 2.0$ & $67.2 \pm 9.5$ & $69.9 \pm 3.7$ & $47.4 \pm 13.0$ & $45.9 \pm 3.8$ \\
\hline \multicolumn{7}{|l|}{ Branched } \\
\hline i16:0 & 0 & $0.4 \pm 0.4$ & 0 & $0.4 \pm 0.2$ & $1.4 \pm 0.7$ & $0.6 \pm 0.6$ \\
\hline $\mathrm{i} 17: 0$ & 0 & 0 & 0 & 0 & $0.1 \pm 0.1$ & 0 \\
\hline Total & 0 & $0.4 \pm 0.4$ & 0 & $0.4 \pm 0.2$ & $1.5 \pm 0.9$ & $0.6 \pm 0.6$ \\
\hline \multicolumn{7}{|l|}{ Monosaturated } \\
\hline $16: 1 \omega 9 \mathrm{c}$ & 0 & 0 & 0 & $0.2 \pm 0.1$ & $0.4 \pm 0.2$ & 0 \\
\hline $16: 1 \omega 7 \mathrm{C}$ & $11.1 \pm 1.7$ & $7.6 \pm 0.3$ & $5.3 \pm 1.2$ & $3.0 \pm 0.7$ & $1.4 \pm 0.9$ & $1.0 \pm 0.6$ \\
\hline $16: 1 \omega 5 c$ & 0 & 0 & 0 & $0.1 \pm 0.0$ & 0 & 0 \\
\hline $17: 1 \omega 8$ & $0.4 \pm 0.4$ & $0.1 \pm 0.1$ & $0.2 \pm 0.2$ & $0.1 \pm 0.1$ & $0.8 \pm 0.4$ & 0 \\
\hline $17: 1 \omega 6$ & 0 & $0.1 \pm 0.1$ & 0 & 0 & $0.9 \pm 0.5$ & $0.3 \pm 0.2$ \\
\hline $18: 1 \omega 9 c^{a}$ & $25.3 \pm 1.3$ & $16.7 \pm 0.6$ & $19.0 \pm 1.0$ & $14.7 \pm 2.3$ & $18.7 \pm 2.6$ & $23.9 \pm 1.9$ \\
\hline $18: 1 \omega 7 \mathrm{C}$ & $0.9 \pm 0.2$ & $0.4 \pm 0.1$ & $3.1 \pm 0.0$ & $3.2 \pm 0.5$ & $5.3 \pm 3.6$ & $0.2 \pm 0.2$ \\
\hline $19: 1$ & 0 & 0 & 0 & $0.5 \pm 0.5$ & $0.3 \pm 0.3$ & 0 \\
\hline $20: 1 \omega 9 c+20: 3 \omega 3$ & 0 & $0.5 \pm 0.5$ & 0 & 0 & 0 & $0.1 \pm 0.1$ \\
\hline $22: 1 \omega 11+13$ & 0 & $3.0 \pm 0.9$ & 0 & 0 & 0 & 0 \\
\hline Total & $37.8 \pm 3.6$ & $28.5 \pm 2.6$ & $27.6 \pm 2.4$ & $21.8 \pm 4.2$ & $27.8 \pm 8.5$ & $25.5 \pm 3.1$ \\
\hline \multicolumn{7}{|l|}{ Polyunsaturated } \\
\hline $18: 3 \omega 6$ & 0 & $0.1 \pm 0.1$ & $0.2 \pm 0.2$ & 0 & 0 & 0 \\
\hline $18: 4 \omega 3$ & $1.5 \pm 0.8$ & $2.9 \pm 0.2$ & 0 & 0 & 0 & 0 \\
\hline $18: 2 \omega 6$ & $2.6 \pm 0.3$ & $3.4 \pm 0.5$ & $0.4 \pm 0.4$ & $2.1 \pm 1.0$ & $13.0 \pm 6.5$ & $25.4 \pm 3.4$ \\
\hline $20: 4 \omega 6$ & $6.8 \pm 1.3$ & $7.3 \pm 0.8$ & $1.8 \pm 1.0$ & $2.3 \pm 1.6$ & 0 & $0.3 \pm 0.3$ \\
\hline $20: 5 \omega 3$ & $0.9 \pm 0.3$ & $2.3 \pm 0.1$ & $2.6 \pm 1.5$ & $1.8 \pm 1.2$ & 0 & 0 \\
\hline $20: 3 \omega 6$ & $0.1 \pm 0.1$ & $0.4 \pm 0.2$ & $0.2 \pm 0.2$ & 0 & 0 & $0.1 \pm 0.1$ \\
\hline $20: 4 \omega 3$ & 0 & $2.2 \pm 1.2$ & 0 & 0 & 0 & $0.5 \pm 0.5$ \\
\hline $20: 2 \omega 6$ & 0 & $1.2 \pm 0.6$ & 0 & 0 & 0 & $0.1 \pm 0.1$ \\
\hline C21 PUFA & 0 & 0 & 0 & 0 & 0 & $0.1 \pm 0.1$ \\
\hline $22: 4 \omega 6$ & 0 & 0 & 0 & 0 & 0 & $0.2 \pm 0.2$ \\
\hline Total & $11.9 \pm 2.9$ & $19.9 \pm 3.6$ & $5.2 \pm 3.3$ & $6.2 \pm 3.8$ & $13.0 \pm 6.5$ & $26.5 \pm 4.5$ \\
\hline \multicolumn{7}{|l|}{ Fatty aldehydes } \\
\hline $16: 0$ & 0 & $0.4 \pm 0.2$ & 0 & 0 & $2.7 \pm 1.3$ & $1.4 \pm 0.4$ \\
\hline $18: 0$ & $1.0 \pm 1.0$ & 0 & 0 & $1.7 \pm 1.5$ & $7.6 \pm 7.6$ & 0 \\
\hline Total & $1.0 \pm 1.0$ & $0.4 \pm 0.2$ & 0 & $1.7 \pm 1.5$ & $10.3 \pm 8.9$ & $1.4 \pm 0.4$ \\
\hline
\end{tabular}


Table 3. Results of permutational MANOVA testing for significance of variation in fatty acid composition among levels of 3 types of macrophytes (divisions) and between species within each division. Bold: statistical significance at $\mathrm{p}<0.05$

\begin{tabular}{|lcccccc|}
\hline Source & df & MS & $F$ & $\begin{array}{c}p \\
\text { (Monte Carlo) }\end{array}$ & $\begin{array}{c}\text { Pseudo-variance } \\
\text { components }\end{array}$ \\
\hline Division & 2 & 2837.80 & 6.95 & $\mathbf{0 . 0 0 3}$ & 404.74 & 56.8 \\
Species (Division) & 3 & 408.54 & 1.59 & 0.162 & 50.40 & 7.0 \\
Residual & 12 & 257.33 & & & 257.33 & 36.1 \\
\hline
\end{tabular}

rate levels of $16: 1 \omega 7 \mathrm{C}(2.7$ to $3.4 \%)$ and $18: 1 \omega 7 \mathrm{C}$ $(2.5$ to $5.9 \%)$ were also present in consumers. Of the essential fatty acids (PUFA), consumers contained

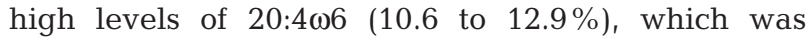
also present in moderate levels in brown algae. Amphipods also contained moderate levels of 18:4 $\omega 3$ $(2.3 \%)$, which occurred predominantly in brown algae (Fig. 5).

The nMDS ordination using essential fatty acid data ( $\omega 3$ and $\omega 6$ PUFA) grouped consumers (amphipods and fish) together to the bottom left of the ordination plot (Fig. 6). Brown algae were grouped together in the centre of the ordination, close to the consumers. Seagrasses were grouped together on the bottom right of the ordination plot, while red algae were dispersed across the top of the ordination. SIMPER revealed that the average dissimilarity in essential fatty acid composition between the amphipod Allorchestes compressa and each of the macrophyte taxa was highest for seagrass $(83.8 \%)$, followed by red algae $(63.4 \%)$ and was

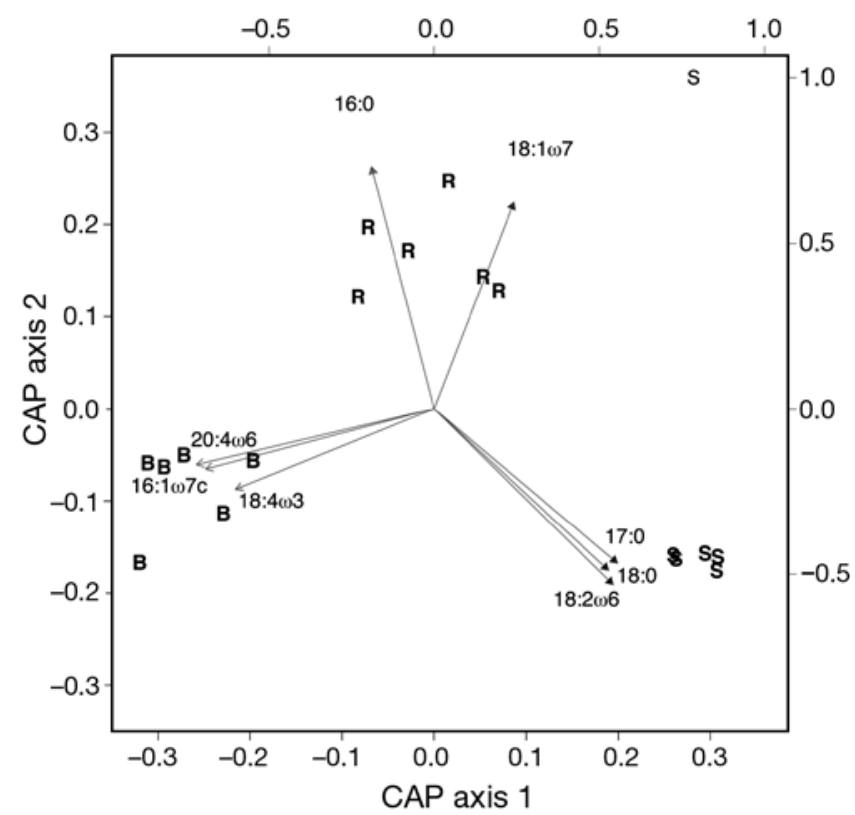

Fig. 4. Constrained ordination (canonical analysis of principal coordinates, CAP) of detached macrophytes: seagrass (S), red algae (R) and brown algae (B) derived from Bray-Curtis dissimilarities calculated from fatty acid compositions lowest for brown algae (38.3\%). Average dissimilarity between amphipods and fish was low (28.3\%), suggesting similar essential fatty acid composition between consumers.

\section{DISCUSSION}

The present study documents that the mesograzer Allorchestes compressa and the fishes Cnidoglanis macrocephalus and Pelsartia humeralis, abundant consumers of amphipods in the surf zone of southwestern Australia (Crawley et al. 2006), rely predominantly on the input of allochthonous brown algae. Despite the large biomass of several different types of marine macrophytes in the surf zone (brown and red algae and seagrass), brown algae were the main food source for amphipods. Since these consumers reach far greater densities in accumulations of wrack than in bare sand in this environment (Robertson \& Lucas 1983, Crawley \& Hyndes 2007), this allochthonous material provides a 'spatial subsidy' for consumers in the surf zone, where in situ primary production is low.

We employed a combination of analyses using stable isotopes and fatty acids, but stable isotopes provided less clarity than fatty acids. This was due to the overlap in $\delta^{13} \mathrm{C}$ among macrophytes, which was exacerbated when known levels of discrimination for Allorchestes compressa were applied prior to using data in mixing models. $\delta^{13} \mathrm{C}$ could help distinguish between macroalgae and seagrass, but not between brown and red macroalgae. Seagrasses had higher $\delta^{13} \mathrm{C}$ values than macroalgae, which has been shown for the same species elsewhere (Smit et al. 2006) and for other seagrass species (Nichols et al. 1985). However, when $\delta^{13} \mathrm{C}$ discrimination of $-10 \%$ for seagrass and $+3 \%$ for macroalgae were applied (Crawley et al. 2007), results of mixing models were ambiguous and were unable to clearly resolve the relative contributions of seagrass or macroalgae to the diet of $A$. compressa. This ambiguity was not resolved through the use of $\delta^{15} \mathrm{~N}$ and $\delta^{34} \mathrm{~S}$, both of which varied little between seagrasses and macroalgae, and therefore contributed little to distinguishing the sources of production for consumers. This is not surprising for $\delta^{15} \mathrm{~N}$, which is generally similar for 

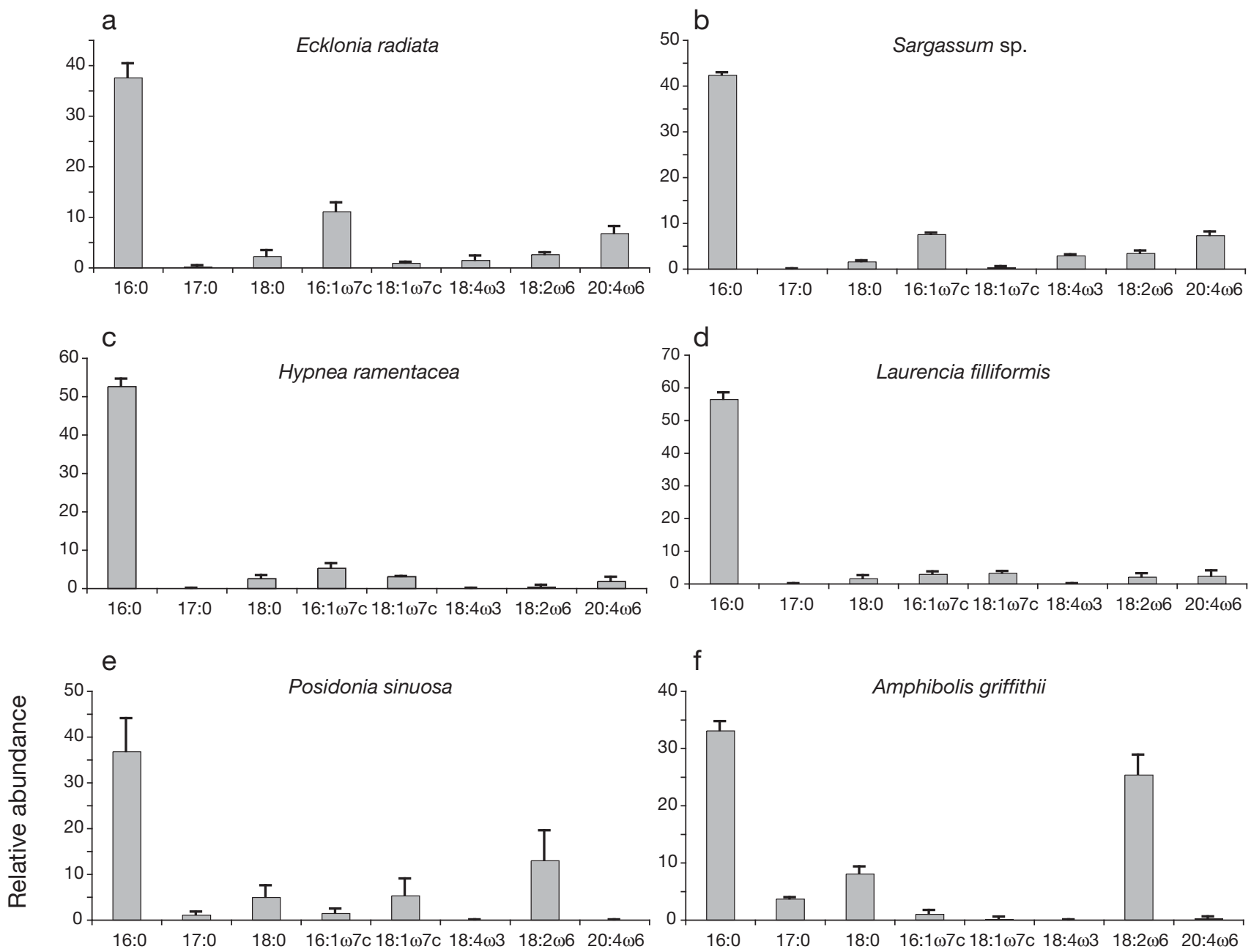
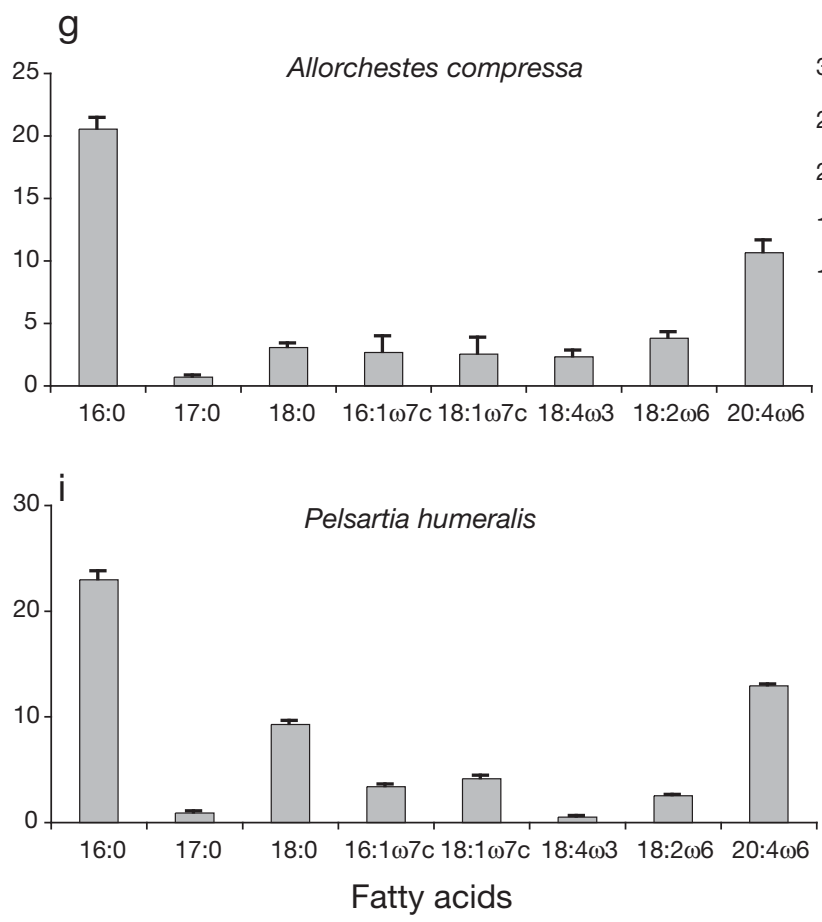

h

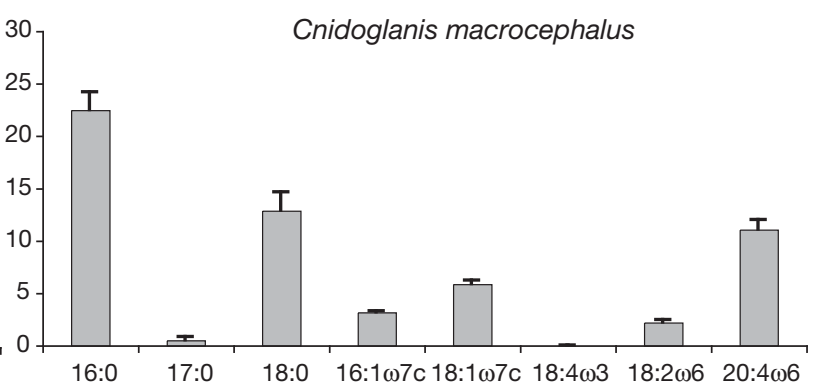

Fatty acids
Fig. 5. Relative proportions of diagnostic fatty acids (average + SE) identified by CAP analysis for the macrophytes $(a, b)$ brown algae, $(\mathrm{c}, \mathrm{d})$ red algae, $(\mathrm{e}, \mathrm{f})$ seagrasses, and for $(\mathrm{g})$ amphipods and $(\mathrm{h}, \mathrm{i})$ fishes 


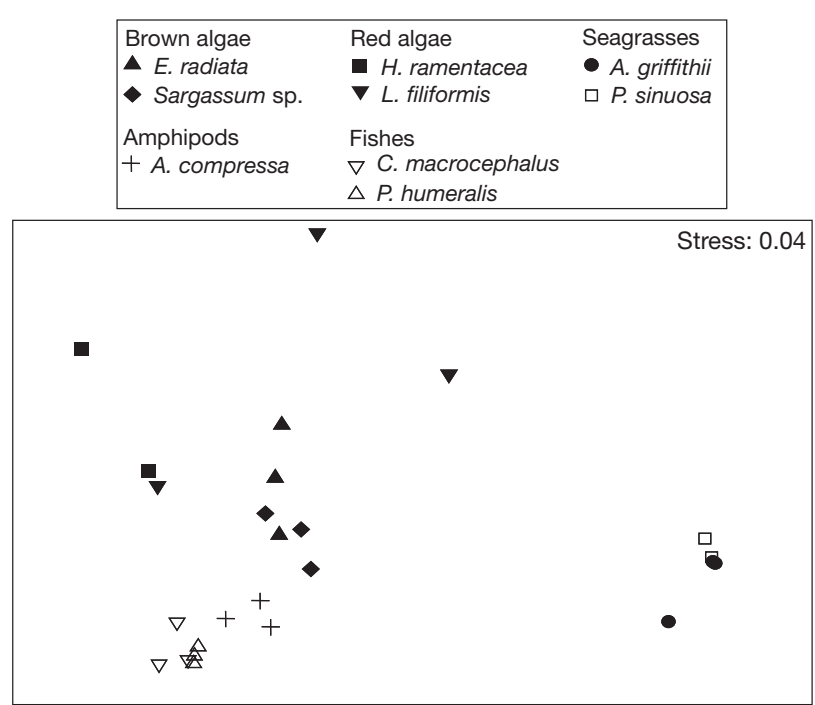

Fig. 6. Two-dimensional non-metric multi-dimensional scaling (nMDS) ordination of essential fatty acid profiles for macrophytes (brown and red algae and seagrasses), amphipods and fishes from 3 sites in southwestern Australia. For full taxonomic names see 'Materials and methods - Study area and sample collection'

organisms within the same trophic level, yet differs between organisms at different trophic levels and therefore can be used to help construct trophic relationships (Vander Zanden \& Rasmussen 1999). While this trophic shift was evident between primary producers and primary consumers (amphipods), there was no distinction in $\delta^{15} \mathrm{~N}$ between consumer groups. In the case of $\delta^{34} \mathrm{~S}$, the lack of differences between seagrasses and macroalgae contrasts with other marine food web studies, where the combination of $\delta^{13} \mathrm{C}$ and $\delta^{34} \mathrm{~S}$ could separate marine vascular plants from algae more than any other combination of $\delta^{13} \mathrm{C}, \delta^{15} \mathrm{~N}$ and $\delta^{34} \mathrm{~S}$ (Connolly et al. 2004). However, $\delta^{34} \mathrm{~S}$ appears to be more discriminating in semi-enclosed coastal systems, such as estuaries, where the $\delta^{34} \mathrm{~S}$ values of rooted plants, e.g. saltmarshes, in anaerobic sediments are influenced by the bacterial reduction of sulphates (Fry et al. 1982). Results from the present study suggest that stable isotopes are less discerning in more open marine systems such as the coastal marine waters of southwestern Australia.

In comparison to the stable isotope results, the fatty acid compositions of brown algae, red algae and seagrass were distinct, therefore providing a useful biomarker to examine trophic connectivity to consumers. Marine macrophytes are rich in $\omega 3$ and $\omega 6$ PUFA, which are essential fatty acids for animals and are considered to be good indicators of diet, as they cannot be produced de novo by animals (Sanina et al. 2004). Marine crustaceans are particularly rich in

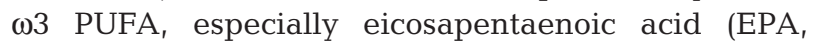

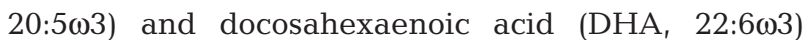
(Chamberlain et al. 2004), and $\omega 6$ PUFA, especially

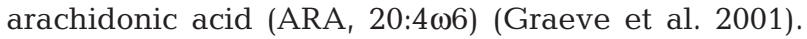
The $\omega 3$ and $\omega 6$ PUFA composition of Allorchestes compressa was most similar to that of brown algae and most dissimilar to that of seagrass, indicating that many of these essential fatty acids were derived from allochthonous brown algae. Amphipods were characterised by moderate to high levels of arachidonic (ARA,

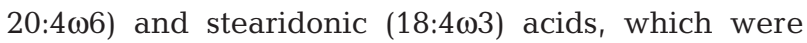
abundant in brown algae but absent in seagrass. Similarly, A. compressa contained eicosapentaenoic acid (EPA) (20:5 03$)$, which was present only in brown and red algae, whereas levels of linoleic acid $(3.8 \%$,

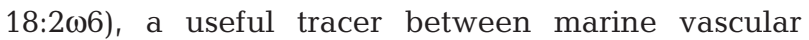
plants and crustaceans (Hall et al. 2006), were very low in amphipods but high in seagrass. These results provide evidence that nutrients primarily from allochthonous brown algae are assimilated by $A$. compressa.

The finding that amphipods consumed mainly brown algae is supported by stable isotope results, although these could not discount other alternatives. However, feeding preference experiments with Allorchestes compressa have shown a very clear grazing preference by this amphipod for brown algae (Crawley \& Hyndes 2007), further strengthening the conclusion of the present study. Decomposition and bacterial degradation of different plant material in wrack, and any associated shift in food choice by $A$. compressa, is unlikely to affect the conclusions of the present study. In previous studies on the feeding preference of $A$. compressa for fresh or decomposed seagrass (Posidonia sinuosa) and brown algae (Ecklonia radiata), plant type (seagrass, brown algae or red algae) had a greater influence on the stable isotope ratios of $A$. compressa than the state of decomposition of the macrophyte material (Crawley et al. 2007). Similarly, there was little difference in the fatty acid composition of amphipods, which had fed on either fresh or decomposed plant material (K. R. Crawley unpubl. data).

The EFA composition of the fishes Cnidoglanis macrocephalus and Pelsartia humeralis was similar to Allorchestes compressa, consistent with the view that this amphipod forms a major component of the diet of these 2 species (Crawley et al. 2006). The close similarity in the $\delta^{13} \mathrm{C}$ values and EFA profiles of $A$. compressa and juvenile $C$. macrocephalus and $P$. humeralis in the present study, coupled with the high consumption of this amphipod by these fish species ( Crawley et al. 2006), indicates that the amphipods provide an important link in the flow of nutrients and energy from allochthonous brown algae to higher levels in the food web in the surf zone of the region. Brown algae are therefore the predominant ultimate sources of production in the food web of the surf zone, despite contributing only 17 to $28 \%$ of the dry bio- 
mass of wrack at the sites during the study period. In contrast, seagrass made up the bulk (52 to $58 \%$ ) of the biomass of wrack, but contributed little to the diet of amphipods. Allochthonous brown algae, therefore, appears to provide a disproportionate role in supporting the food chain in the surf zone of the region, where amphipod and fish abundances are clearly enhanced by increasing volumes of wrack (Robertson \& Lucas 1983, Crawley et al. 2006). Brown algae in this environment are also likely to benefit amphipods and fish by providing shelter from predation (Crawley et al. 2006, Crawley \& Hyndes 2007), whereas the role of seagrass appears to be restricted to providing habitat.

Trophic linkages across habitats through the movement of nutrients, detritus or organisms can be crucial to the productivity of many coastal ecotones (Polis et al. 1997). While several studies have focused on linkages between terrestrial and marine systems (see Polis et al. 1997), the present study clearly shows a strong link between habitats that produce a mosaic landscape in the marine environment, i.e. reefs and sandy surf zones. Brown algae, particularly Ecklonia radiata, are dislodged and transported from reefs to other habitats through water movement (Wernberg et al. 2006). This detached material has been suggested to be an important food source for grazer species in other habitats in southwestern Australia (Vanderklift \& Kendrick 2005, Wernberg et al. 2006) and elsewhere (Pennings et al. 2000). For the first time, the use of both stable isotopes and fatty acids has allowed us to establish that inputs of brown algae into the surf zone subsidises secondary production in that habitat, which otherwise contains little in situ production. Since the reefs occur approximately 1 to $20 \mathrm{~km}$ from the surf zone, the spatial extent of the connectivity between these ecotones is relatively large.

Detached macrophytes accumulate along shorelines in many parts of the world and those accumulations can comprise a mixture of different types of macrophytes (Colombini \& Chelazzi 2003). The present study clearly shows that different types of macrophytes can play substantially different roles in these ecotones, with brown algae playing a particularly important role in fueling secondary production. To maintain the integrity of the flow of nutrients from donor to recipient habitats within the marine environment, spatial management approaches need to incorporate spatial extents that can preserve these integral processes.

Acknowledgements. We thank J. Tranter at Edith Cowan University (ECU) for IRMS assistance and CSIRO Marine and Atmospheric Research in Tasmania for assistance with fatty acid analyses. We acknowledge P. Kindleysides for cartographic assistance (Fig. 1) and L. Horn for editorial comments. We also appreciate the help of C. Doropoulos and R. Phleger for preparing and analysing the fatty acid samples for the drying treatment comparisons, and P. Moore for analyses of those data. N. Loneragan, A. McLachlan and J. Valentine provided useful comments on earlier drafts of this manuscript, and comments from $\mathrm{M}$. Pederson and 3 anonymous reviewers improved the manuscript. We acknowledge financial support from the Centre for Ecosystem Management of ECU and CSIRO Strategic Research Fund for the Marine Environment (to K.R.C.). The experiments performed in this study comply with the current laws of Australia.

\section{LITERATURE CITED}

Anderson MJ (2001) A new method for non-parametric multivariate analysis of variance. Austral Ecol 26:32-46

> Anderson MJ, Millar RB (2004) Spatial variation and effects of habitat on temperate reef fish assemblages in northeastern New Zealand. J Exp Mar Biol Ecol 305:191-221

Anderson MJ, Willis TJ (2003) Canonical analysis of principal coordinates: a useful method of constrained ordination for ecology. Ecology 84:511-525

Bligh EG, Dyer WM (1959) A rapid method of total lipid extraction and purification. Can J Biochem Physiol 35: 911-917

Boutton TW (1991) Stable carbon isotope ratios of natural materials. I. Sample preparation and mass spectrometric analysis. In: Coleman DC, Fry B (eds) Carbon isotope techniques. Academic Press, San Diego, p 155-171

Brown AC, McLachlan A (1990) Ecology of sandy shores. Elsevier, The Netherlands

Chamberlain PM, Bull ID, Black HIJ, Ineson P, Evershed RP (2004) Lipid content and carbon assimilation in Collembola: implications for the use of compound-specific isotope analysis in animal dietary studies. Oecologia 139:325-335

Clarke KR, Gorley RN (2001) Primer v5: User manual/tutorial. Primer-E, Plymouth

Colombini I, Chelazzi L (2003) Influence of marine allochthonous input on sandy beach communities. Oceanogr Mar Biol Annu Rev 41:115-159

Connolly RM, Guest MA, Melville AJ, Oakes JM (2004) Sulfur stable isotopes separate producers in marine food-web analysis. Oecologia 138:161-167

Crawley KR, Hyndes GA (2007) The role of different types of detached macrophytes in the food and habitat choice of a surf-zone inhabiting amphipod. Mar Biol 151:1433-1443

Crawley KR, Hyndes GA, Ayvazian SG (2006) The influence of different volumes and types of detached macrophytes on fish community structure in surf zones of sandy beaches. Mar Ecol Prog Ser 307:233-246

Crawley KR, Hyndes GA, Vanderklift MA (2007) Variation among diets in discrimination of $\delta^{13} \mathrm{C}$ and $\delta^{15} \mathrm{~N}$ in the amphipod Allorchestes compressa. J Exp Mar Biol Ecol 349:370-377

> Fry B, Scalan RS, Winters JK, Parker PL (1982) Sulphur uptake by salt grasses, mangroves and seagrasses in anaerobic sediments. Geochim Cosmochim Acta 46: $1121-1124$

Graeve M, Dauby P, Scailteur Y (2001) Combined lipid, fatty acid and digestive tract content analyses: a penetrating approach to estimate feeding modes of Antarctic amphipods. Polar Biol 24:853-862

Graham MH, Edwards MS (2001) Statistical significance versus fit: estimating the importance of individual factors in ecological analysis of variance. Oikos 93:505-513

Hall D, Lee SY, Meziane T (2006) Fatty acids as trophic tracers in an experimental estuarine food chain: tracer transfer. J Exp Mar Biol Ecol 336:42-53 
Hyndes GA, Lavery PS (2005) Does transported seagrass provide an important trophic link in unvegetated, nearshore areas? Estuar Coast Shelf Sci 63:633-643

Ince R, Hyndes GA, Lavery PS, Vanderklift MA (2007) Marine macrophytes directly enhance abundances of sandy beach fauna through provision of food and habitat. Estuar Coast Shelf Sci 74:77-86

Kirkman H, Kendrick GA (1997) Ecological significance and commercial harvesting of drifting and beach-cast macroalgae and seagrasses in Australia: a review. J Appl Phycol 9:311-326

Lemm AJ, Hegge BJ, Masselink G (1999) Offshore wave climate, Perth (Western Australia), 1994-96. Mar Freshw Res 50:95-102

Lepoint G, Nyssen F, Gobert S, Dauby P, Bouquegneau JM (2000) Relative impact of a seagrass bed and its adjacent epilithic algal community in consumer diets. Mar Biol 136:513-518

Mansour MP, Holdsworth DG, Forbes SE, Macleod CK, Volkman JK (2005) High contents of 24:6(n-3) and 20:1(n-13) fatty acids in the brittle star Amphiura elandiformis from Tasmanian coastal settlements. Biochem Syst Ecol 33:659-674

Moncreiff CA, Sullivan MJ (2001) Trophic importance of epiphytic algae in subtropical seagrass beds: evidence from multiple stable isotope analyses. Mar Ecol Prog Ser 215:93-106

Nichols PD, Klumpp DW, Johns RB (1985) A study of food chains in seagrass communities. III. Stable carbon isotope ratios. Aust J Mar Freshw Res 36:683-690

Pennings SC, Carefoot TH, Zimmer M, Danko JP, Ziegler A (2000) Feeding preferences of supralittoral isopods and amphipods. Can J Zool 78:1918-1929

Peterson BJ, Howarth RW (1987) Sulfur, carbon and nitrogen isotopes used to trace organic matter flow in the saltmarsh estuaries of Sapelo Island, Georgia. Limnol Oceanogr 32:1195-1213

Phillips DL, Gregg JW (2003) Source partitioning using stable isotopes: coping with too many sources. Oecologia 136: 261-269

Editorial responsibility: Morten Pedersen,

Roskilde, Denmark
Phleger CF, Nichols PD, Virtue P (1998) Lipids and trophodynamics of Antarctic zooplankton. Comp Biochem Physiol B 120:311-323

Phleger CF, Young JW, Guest M, Lansdell M, Nichols PD (2007) Signature fatty acids: a robust method for evaluating trophic relationships in open ocean ecosystems. In: Olson RJ, Young JW (eds) Report of a GLOBECCLIOTOP/PFRP workshop on the role of squid in open ocean ecosystems, 16-17 November 2006, Honolulu, Hawaii, USA. GLOBEC Report 24, p 64-67

Polis GA, Hurd SD (1996) Allochthonous input across habitats, subsidized consumers, and apparent trophic cascades: examples from the ocean-land interface. In: Polis GA, Winemiller KO (eds) Food webs: integration of patterns and dynamics. Chapman \& Hall, London, p 275-285

Polis GA, Anderson TW, Holt RD (1997) Toward an integration of landscape and food web ecology. Annu Rev Ecol Syst 28:289-316

> Robertson AI, Lucas JS (1983) Food choice, feeding rates, and the turnover of macrophyte biomass by a surf-zone inhabiting amphipod. J Exp Mar Biol Ecol 72:99-124

> Sanina NM, Goncharova SN, Kostetsky EY (2004) Fatty acid composition of individual polar lipid classes from marine macrophytes. Phytochemistry 65:721-730

Smit AJ, Brearley A, Hyndes GA, Lavery PS, Walker DI (2006) $\delta^{15} \mathrm{~N}$ and $\delta^{13} \mathrm{C}$ analysis of a Posidonia sinuosa seagrass bed. Aquat Bot 84:277-282

> Vanderklift MA, Kendrick GA (2005) Contrasting influence of sea urchins on attached and drift macroalgae. Mar Ecol Prog Ser 299:101-110

> Vander Zanden MJ, Rasmussen JB (1999) Primary consumer $\delta^{13} \mathrm{C}$ and $\delta^{15} \mathrm{~N}$ and the trophic position of aquatic consumers. Ecology 80:1395-1404

Wernberg T, Vanderklift MA, How J, Lavery PS (2006) Export of detached macrophytes from reefs to adjacent seagrass beds. Oecologia 147:692-701

Wilson SK, Burns K, Codi S (2001) Sources of dietary lipids in the coral reef blenny Salarias patzneri. Mar Ecol Prog Ser 222:291-296

Submitted: January 9, 2008; Accepted: October 31, 2008 Proofs received from author(s): February 2, 2009 